DOI: $10.17805 /$ zpu.2017.3.19

\title{
Оптимизация стратегии вуза в области реализации новых программ рекрутинга студентов
}

\author{
Н. В. АВРАЛЕВ, И. Н. ЕФИМОВА, А. В. МАКОВЕЙЧУК \\ НАЦИОНАЛЬНЫЙ ИССЛЕДОВАТЕЛЬСКИЙ НИЖЕГОРОДСКИЙ ГОСУДАРСТВЕННЫЙ УНИВЕРСИТЕТ \\ ИМ. Н. И. ЛОБАЧЕВСКОГО
}

Данная статья посвящена исследованию эффективности комплекса профориентационных мероприятий нового формата и практики внедрения инновационных подходов в работе с абитуриентами в условиях возрастания конкуренции в сфере высшего образования в России. В числе ключевых мероприятий в комплексе - создание механизмов для развития исследовательской деятельности школьников и формирование системы непрерывного образования «школа - вуз». В статье проанализированы лучшие практики, реализуемые Национально-исследовательским Нижегородским государственным университетом им. Н. И. Лобачевского (ННГУ им. Н. И. Лобачевского) в данной области.

В качестве эмпирической базы в статье использованы локальные документы ННГУ им. Н. И. Лобачевского, посвященные реализации программы «Университетский кластер образования» и другим профориентационным мероприятиям, реализуемым в ННГУ. Также приводятся результаты социологических исследований, проведенных в университете в период летних приемных кампаний 2011-2016 гг. В целях сбора первичной информации был выбран метод анкетирования, который является достаточно эффективным, наглядным и самым распространенным способом мониторинга потребителей образовательных услуг.

К определяющим причинам, оказывающим влияние на выбор абитуриентами того или иного вуза для обучения, относятся наличие бюджетных мест на интересующих их направлениях, местонахождение университета, его материально-техническая база, научные успехи и престиж.

Сформулированы выводы и предложения по оптимизации профориентационной программы университета, реализации новых мероприятий и форматов деятельности по привлечению в университет талантливых абитуриентов. Так, главными направлениями развития здесь становятся расширение и углубление партнерских связей с ведущими школами региона, реализация совместных специальных научно-популярных мероприятий в формате опен-эйров, проведение научно-исследовательских клубов и викторин с участием высокоцитируемых ученых.

Ключевые слова: университетский кластер образования; технологии рекрутинга; профориентация; высшее образование; студенты; рекрутинг

\section{ВВЕАЕНИЕ}

ктуальность создания единой системы профориентационной работы с обучаюАщимися разных уровней образования (общее (школа), высшее (бакалавриат, магистратура, аспирантура), послевузовское (дополнительное образование и профессиональная переподготовка)) обусловлена новыми вызовами научно-технологического развития страны в условиях жесточайшей конкуренции за высококвалифицированных специалистов на глобальном рынке труда. Необходимо преодоление институциональных и психологических барьеров в образовательной цепочке: школа - университет - работодатель. Это позволит сформировать единую экосистему непрерывной подготовки «специалиста будущего» - профессионала, способного решать задачи в мультидисциплинарных коллективах. Подготовка такого специалиста возможна лишь в условиях опережающей профориентации, позволяющей на стадии общего образования как можно раньше определить способности ребенка к определенным предметам и содействовать их развитию посредством различных форм включения обучающегося в сферу деятельности университета. Основной целью опережающей 
профориентации в условиях непрерывного образования является формирование единой информационно-образовательной среды, способствующей созданию әффективной системы ранней профориентации, выявлению и сопровождению одаренных детей и молодежи в условиях больших вызовов по решению задач научно-технологического развития России.

Проблему особенностей спроса на высшее образование в России в своих исследованиях поднимает Г. А. Колесникова (Колесникова, 2009), отмечая, что образование является одной из важнейших подсистем социальной сферы государства, обеспечивающей процесс получения человеком систематизированных знаний, умений и навыков с целью их эффективного использования в профессиональной деятельности. Объективный анализ потребностей абитуриентов и факторов, влияющих на выбор образовательного учреждения, определит перспективы развития маркетинга образовательных услуг и наметит пути совершенствования системы управления университетом для максимального удовлетворения запросов потребителей образовательных услуг.

Опыт американских университетов в определении оптимальных стратегий работы с потенциальными абитуриентами исследует в своей работе Ф. Вайтхед (Whitehead, 2012: Электронный ресурс). Вопросы эффективного рекрутинга в ряды студентов наиболее одаренных из них, повышения престижа обучения в вузе, формирования маркетинговой политики в области развития новых специальностей и сохранения имеющихся исследуют в своей работе Н. В. Авралев и И. Н. Ефимова (Avralev, Efimova, 2015). Интересно исследование П. Рассела, в котором затрагиваются вопросы налаживания долгосрочных и взаимовыгодных отношений с крупными работодателями в части использования их практической базы, стажировок и трудоустройства выпускников вуза (Russell, 2011: Электронный ресурс).

В работе Аж. Аудерштадта затронуты вопросы становления и развития исследовательских университетов в современном мире, гибко реагирующих на общественные запросы, формирующих инновационное образовательное пространство вокруг себя; также уделено внимание вопросам влияния технологического прогресса на сферу образования и исследований и тому, как современные цифровые технологии могут способствовать развитию административно-управленческих структур университетов и реализации их маркетинговой политики. Одним из обязательных условий эффективного функционирования высшего учебного заведения в современном мире является его ориентация на потребителя образовательных услуг, а именно абитуриентов, реализация клиентоориентированного подхода (Duderstadt, 2014).

Аругой исследователь проблем применения цифровых технологий и социальных медиа Аж. Шоу в своем блоге на сайте газеты «Гардиан» приводит результаты исследования, проведенного среди текущих и потенциальных студентов вузов, посвященного влиянию различных источников информации на выбор учебного заведения (Shaw, 2013: Электронный ресурс). Исследование представляло собой онлайн-анкетирование, в котором приняло участие около 300 человек. Одним из главных результатов исследования стало то, что, несмотря на активное ежедневное использование социальных медиа (почти $65 \%$ респондентов отметили данный факт), процент респондентов, доверяющих информации об университетах, полученной из социальных медиа, меньше количества тех респондентов, кто доверяет информации, полученной на днях открытых дверей в вузах и из информационных печатных материалов (буклетов, лифлетов, брошюр вузов и т. А.). Мнение абитуриентов имеет существенное значение при оценке качества деятельности того или иного вуза. 
В сфере высшего образования России наблюдается высокая конкуренция между вузами, как государственными, так и негосударственными, в борьбе за привлечение талантливых абитуриентов. Вместе с тем немаловажным является и тот факт, что значительный сегмент образования в России представляют платные образовательные услуги. Востребованность той или иной образовательной программы, помимо среднего балла ЕГЭ, определяется и количеством внебюджетных мест студентов, обучающихся по данному направлению подготовки (специальности). Поэтому проведение социологических и маркетинговых исследований в данной сфере необходимо в целях изучения интересов потенциальных потребителей образовательных услуг вуза.

В исследовании С. Э. Шульца процесс выстраивания взаимодействия с потенциальными студентами вуза рассматривается в концепции игры, где, как и в любой игре, существуют определенные стратегии и приемы, необходимые для достижения выигрышного положения (Schulz, 2006: Электронный ресурс). Поэтому и стратегия работы с абитуриентами должна строиться на четком понимании их запросов и гибкой адаптации к любым изменениям предпочтений (интересов и т. А.).

На систему высшего образования в России оказывают существенное влияние глобализационные процессы, которые привели к значительному увеличению спроса на качественное высшее образование на международном рынке услуг. Вместе с тем на внутреннем рынке ведущие университеты страны в связи с неблагоприятными демографическими процессами находятся в состоянии жесточайшей конкуренции за талантливых абитуриентов и внебюджетного студента. В этой связи необходимы совершенно новые формы и технологии профориентационной деятельности вуза, охватывающие как индивидуальную работу с талантливыми школьниками, так и массовые проекты, позволяющие включить в сферу деятельности университета как можно большее количество детей.

Целью написания данной статьи является систематизация опыта реализации профориентационных программ университета начиная с 2011 г., анализ механизмов взаимодействия между потенциальными абитуриентами и университетом, а также описание полученных результатов в ходе многолетних исследований рынка образовательных услуг Нижегородской области. Новизна работы заключается в формулировании новых подходов в реализации профориентационных мероприятий университета, в том числе и с привлечением актуальных сегодня возможностей интернет-технологий, в частности социальных медиа и иных интерактивных онлайн-ресурсов.

В качестве эмпирической базы в статье использованы локальные документы ННГУ им. Н. И. Аобачевского, посвященные реализации программы «Университетский кластер образования» и другим профориентационным мероприятиям, реализуемым в ННГУ. Также приводятся результаты социологических исследований, проведенных в университете в период летних приемных кампаний 2011-2016 гг. В целях сбора первичной информации был выбран метод анкетирования, который является достаточно эффективным, наглядным и самым распространенным способом мониторинга потребителей образовательных услуг.

\section{СОЗААНИЕ ИННОВАЦИОННОЙ СИСТЕМЫ ПРОФОРИЕНТАЦИОННОЙ АЕЯТЕАЬНОСТИ В ННГУ}

Национальный исследовательский Нижегородский государственный университет им. Н. И. Аобачевского всегда уделял и уделяет большое внимание развитию профориентационной деятельности, взаимодействию с ведущими школами Нижнего Новго- 
рода и Нижегородской области, участию в организации всероссийских олимпиад школьников и т. А. в целях формирования потенциального контингента обучающихся и привлечения в университет талантливых абитуриентов. С 2013 г. здесь действует уникальная в своем роде программа «Университетский кластер образования», задачей которой является создание «школы будущего», ориентированной на развитие инициативы обучающихся, способности творчески мыслить, находить нестандартные решения. В рамках этой программы университет формирует сквозную систему обеспечения качества школьного образования, обеспечивает проведение спецкурсов, факультативов, руководство учебно-исследовательскими работами школьников с использованием современной научно-образовательной инфраструктуры университета. Учредителями кластера, помимо ННГУ, стали 10 ведущих школ Нижнего Новгорода и области, большинство из которых регулярно с 2013 г. попадают в топ-500 лучших школ России. Отдельным направлением работы в рамках проекта «Университетский кластер образования» является системная работа университета по созданию на базе опорных школ ННГУ профильных университетских классов.

Статистика приемных кампаний 2013-2016 гг. показывает, что выпускники школ «Университетского кластера образования» занимают до 25\% всех бюджетных мест в ННГУ. Причем практически все эти выпускники с очень высокими баллами, которые позволяют поступать в другие ведущие вузы России. Анализ результатов социологических исследований 2011-2016 гг., проведенных сотрудниками отдела по связям с общественностью и интернет-коммуникациям ННГУ среди абитуриентов ННГУ, показал, что выпускники школ «Университетского кластера образования» более мотивированы при выборе будущей профессии и ориентируются на университет, отмечая высокое качество образования и желание учиться именно у тех вузовских преподавателей, которые давали им дополнительные знания по предметам в школе и готовили их к олимпиадам.

В феврале 2014 г. ННГУ и Администрация Нижнего Новгорода заключили договор о реализации пилотного проекта «Университетская школа» в рамках программы «Университетский кластер образования». Основной экспериментальной площадкой данного проекта стала школа № 113 Нижнего Новгорода. Главными задачами проекта является создание на базе данной школы условий для формирования личности, готовой к жизни в высокотехнологичном, конкурентном мире, путем расширения возможностей реализации программ подготовки школьников к получению качественного высшего образования и осознанного профессионального выбора. Также планировалось, что университетская школа станет ресурсным центром для повышения квалификации учителей.

ННГУ взял на себя обязательства в рамках данного проекта включить школу в сферу научно-образовательной и культурной деятельности университета, создать сквозную систему обеспечения качества образования «школа - университет», сделать доступной для учеников и учителей школы современную научно-образовательную инфраструктуру ННГУ, обеспечить силами преподавателей университета преподавание спецкурсов, факультативов, проведение занятий по программам довузовской подготовки учащихся к государственной (итоговой) аттестации и олимпиадам школьников.

Стоит отметить, что главным новшеством данной университетской школы по сравнению с другими подобными учебными заведениями при ведущих вузах России является наличие в структуре университетской школы как средних классов (5-9-е классы), 
так и начальной школы (1-4-е классы). Уже с пятого класса ребят знакомят с физикой и химией на базе созданного в школе научно-познавательного клуба «Кулибин», который был открыт в 2015 г. для школьников начальной школы и пятых - седымых классов. Аля учеников начальной школы существует интегрированный подход, включающий в себя преподавание по математике, физике, химии, биологии, целью которого является познание юными школьниками окружающей среды и окружающего мира посредством вовлечения их в проектную исследовательскую деятельность. Также учащиеся младших классов участвуют в научно-техническом творчестве: весной 2017 г. на базе клуба «Кулибин» проходили фестиваль и выставка творческих работ учащихся младших классов «Начало 8+», в рамках которых были организованы секции по техническому конструированию и робототехнике, работали детская IT-лаборатория и мультстудия. В клубе занимаются как школьники университетской школы, так и учащиеся других школ Нижнего Новгорода. Реализуются программы по совместной проектной деятельности детей вместе со своими родителями. В 2016 г. воспитанники клуба стали победителями всероссийских конкурсов по физике и химии. Ученица шестого класса стала победителем Всероссийского конкурса «Аеонардо», заняв первое место, а ученица пятого класса - лауреатом данного конкурса. В 2017 г. два воспитанника клуба - ученики второго класса - стали призерами и заняли вторые места.

На базе клуба «Кулибин» дан старт реализации новых образовательных практик и тренингов для педагогов, повышающих их квалификацию и расширяющих возможности системы дополнительного образования. При открытии перед клубом ставились задачи по организации совместной деятельности студентов, молодых ученых и специалистов ННГУ с опытными нижегородскими педагогами на всех этапах работы клуба. Сегодня по-прежнему перед клубом стоит основополагающая задача по подготовке талантливых высокомотивированных школьников. Также в перспективе планируется расширение опыта клуба «Кулибин» и на другие учебные заведения Нижегородской области и Приволжского федерального округа и создание единой экспериментальной площадки для подготовки педагогов-наставников с использованием самых передовых образовательных технологий.

В системе профориентационных мероприятий ННГУ большое внимание уделено и работе с педагогическими кадрами в школах. Университет имеет многолетний успешный научно-методический и педагогический опыт по реализации программ повышения квалификации учителей с использованием международно признанных технологий обучения.

Среди многочисленных профориентационных мероприятий, реализуемых университетом, можно выделить масштабный проект по проведению ежегодной городской конференции Научного общества учащихся (НОУ) «Эврика». Основная цель НОУ усиление интереса школьников к научной работе, в том числе под руководством преподавателей ННГУ, и повышение привлекательности университета для старшеклассников. Опыт показывает, что функционирование научного общества учащихся является действенным инструментом профориентационной работы. С 2015 г. участие в городской конференции НОУ «Эврика» учитывается в качестве индивидуальных достижений, дающих дополнительные баллы при поступлении в ННГУ. В 2016 г. $70 \%$ учащихся 11-го класса - участников городской конференции НОУ «Эврика»подали документы в университет и 40\% из них стали студентами. Такая форма работы со школьниками позволяет сформировать у них интерес к исследовательской деятельности, развить их научный и творческий потенциал, а также создать «эффект по- 
гружения» в профессиональную деятельность в выбранной ими сфере знаний. Высокий уровень поступления таких выпускников в университет свидетельствует об осознанности сделанного выбора и хорошем качестве подготовки абитуриентов.

Значительную роль в работе по привлечению в университет талантливых школьников играет олимпиадное движение, в котором принимают участие все образовательные и научные структурные подразделения университета. ННГУ совместно с ведущими региональными вузами России с 2008 г. проводит Межрегиональную олимпиаду школьников «Будущие исследователи - будущее науки». В олимпиаде 2016/2017 учебного года приняли участие 20164 школьника из 40 регионов России и стран СНГ. Существенную долю участников олимпиады составили учащиеся невыпускных (7-10-х) классов. Их число составляет от 60 до $80 \%$ от общего количества участников (в зависимости от предмета). В среднем число финалистов - $30 \%$ от участников отборочного тура, число призеров - $15-20 \%$ от количества финалистов.

Многие победители и призеры олимпиады «Будущие исследователи - будущее науки» являются также призерами других олимпиад: Всероссийской (региональный и всероссийский этап), «Аомоносов», «Шаг в будущее», Межрегиональной олимпиады по математике и криптографии, олимпиады СПбГУ, олимпиады «Нанотехнологии - прорыв в будущее», «Юные таланты», «Росатом», «Физтех», «Покори Воробьевы горы», «Менделеев», «Турнир городов», «Звезда» и других, входящих в Перечень олимпиад школьников, утверждаемый Министерством образования и науки России, а также международных олимпиад и конкурсов.

12 нижегородцев, призеров олимпиады «Будущие исследователи», стали в 2017 г. призерами заключительного этапа Всероссийской олимпиады школьников по физике, математике, информатике, астрономии, истории, экономике, экологии, биологии, русскому языку.

Ежегодно Межрегиональная олимпиада школьников «Будущие исследователи будущее науки» как одна из успешных российских олимпиад с хорошими традициями входит в Перечень олимпиад школьников.

Опыт ННГУ по проведению Межрегиональной олимпиады «Будущие исследователи - будущее науки» и других олимпиад школьников и результаты, которые демонстрируют победители и призеры, уже ставшие студентами университета, говорят о том, что олимпиада также является эффективным механизмом отбора самых одаренных, талантливых, целеустремленных детей. По результатам мониторингов успеваемости на первом курсе данная категория студентов показывает результаты выше, чем все остальные студенты того же курса. Таким образом, олимпиады для школьников являются прекрасной возможностью для абитуриентов поступить в желаемый вуз, а для учебных заведений - получить подготовленных и профессионально ориентированных студентов.

\section{СОЦИОАОГИЧЕСКИЕ ИССАЕАОВАНИЯ \\ КАК ИНСТРУМЕНТ ОЦЕНКИ ЭФФЕКТИВНОСТИ ИМПАЕМЕНТАЦИИ НОВЫХ ТЕХНОАОГИЙ РЕКРУТИНГОВОЙ РАБОТЫ}

В рамках реализации политики университета в области реализации новых форм и методов работы с абитуриентами, формирования комплексного образа университета в школьной среде, а также в рамках задач по определению мотивационных составляющих выбора абитуриентом вуза для обучения с 2011 по 2016 г. в период летних приемных кампаний сотрудниками отдела по связям с общественностью и интер- 
нет-коммуникациям под руководством проректора по связям с общественностью Н. В. Авралева была проведена серия социологических исследований. Результаты исследований 2011-2015 гг. опубликованы в статьях Н. В. Авралева (Avralev, Efimova, 2014, 2015), И. Н. Ефимовой (Ефимова, 2011) и А. В. Маковейчука (Ефимова, Маковейчук, 2013, 2015).

Методом сбора первичной информации в рамках данного исследования является анкетирование. Была разработана анкета, включающая в себя 26 вопросов. Анкета была разработана в 2011 г., дополнена рядом вопросом, в том числе вопросами о рейтингах университетов. В 2012 г. и в последующие годы, включая 2016 г., не менялась. Вопросы затрагивают причины, определяющие привлекательность того или иного высшего учебного заведения, источники получения информации, из каких регионов и населенных пунктов абитуриенты вуза, их предпочтения в выборе направления подготовки, уровень зарплатных притязаний в течение года после окончания вуза и другие вопросы.

Генеральной совокупностью в данном исследовании является численность абитуриентов, подававших заявления в ННГУ в период летних приемных кампаний 2011-2016 гг. (временной интервал 20 июня - 20 июля). Среднее значение генеральной совокупности составляет 10587 человек. Аля расчета объема выборки используем статистический метод. Репрезентативная выборка каждого года составляет не менее 829 человек. В связи с определенными временны'ыми ограничениями и неоднородностью потока абитуриентов объем выборки в разные годы колебался от 853 до 1304 респондентов, что удовлетворяет минимальному значению, необходимому для достижения репрезентативности.

Согласно полученным результатам за 2011-2016 гг. мы можем отметить стабильное превышение количества респондентов девушек (от 54\% в 2011 г. до 67,77\% в 2016 г.) над респондентами юношами (от 46\% в 2011 г. до 32,23\% в 2016 г.). Количество абитуриентов, проживающих непосредственно в городе Нижнем Новгороде и области, поступающих в ННГУ, существенно больше, чем проживающих в городах и населенных пунктах других регионов. Если в 2011 г. количество абитуриентов из Нижегородского региона составляло 62,7\%, то в 2016 г. этот показатель согласно опросу увеличился до 88,8\%. В числе абитуриентов из других регинов необходимо отметить достаточно заметное количество поступающих из Владимирской, Кировской областей, Чувашской Республики и Республики Коми.

Наиболее популярными источниками информации для абитуриентов являются официальный сайт ННГУ им. Н.И. Аобачевского (68\% в 2011 г., 63,45\% в 2016 г.); знакомые, друзья, родные (33,8\% в 2011 г., 52,42\% в 2016 г.); учителя в школе (34\% в 2011 г., 23,9\% в 2016 г.); социальные сети в Интернете (50\% в 2011 г., 18,27\% в 2016 г.). Анализируя ответы, посвященные социальным сетям, необходимо отметить, что в связи с активным развитием официального сайта университета и его интеграции с социальными сетями количество абитуриентов, отождествляющих сайт и аккаунты ННГУ в социальных сетях, с 2011 по 2016 г. существенно возросло. Поэтому отдельно в своих ответах такой источник информации, как социальные сети, был выбран гораздо меньшим количеством респондентов, чем в 2011 г. Пятую позицию в ответах респондентов занимает вариант «информация, полученная из справочной литературы» $(5,1 \%$ в 2011 г., 8,78\% в 2016 г.).

При равных условиях основная часть абитуриентов в качестве главных причин при выборе вуза отмечает советы родителей (показатель менялся с 44\% в 2011 г. до 35,15\% 
в 2016 г.); информацию, полученную от представителей вуза (30\% в 2011 г. и 36,31\% в 2016 г.); советы друзей, знакомых (20,5\% в 2011 г. и 36,46\% в 2016 г.); рекламу вуза (42\% в 2011 г. и 8,09\% в 2016 г.). Пятую позицию в ответах респондентов занимает показатель посещения подготовительных курсов - от 12\% в 2011 г. до 4,85\% в 2016 г.

Необходимо обратить внимание на значительное снижение роли рекламы вуза в ответах респондентов с 2011 по 2016 г. В связи с переформатированием рекламной политики университета и развитием цифровых технологий, в том числе кардинальным обновлением сайта ННГУ в 2014 г. и последующим активным его продвижением в Интернете, а также благодаря реализации новых программ рекрутинга абитуриентов и внедрению более персонализированного подхода в работе со школами, учителями и самими абитуриентами снижается значимость влияния традиционной рекламы на ТВ, радио и в печатных изданиях на поступление в ННГУ.

Проведенный анализ причин поступления абитуриентов в ННГУ им. Н. И. Аобачевского показал, что с 2011 по 2016 г. наблюдается устойчивое снижение спроса на подготовительные курсы. Поэтому в данных условиях становится важным переформатирование профориентационной деятельности с традиционных мероприятий на расширение работы со школами в части реализации совместных образовательных программ, развития ресурсных баз в школах, в том числе и создание научно-познавательных клубов по образцу, как было упомянуто ранее, пилотного проекта клуб «Кулибин», а также реализация новых проектов для будущих абитуриентов, в том числе и с привлечением возможностей дистанционных технологий и социальных медиа.

\section{ЗАКАЮЧЕНИЕ}

Накопленный научный и практический опыт оценки профориентационной деятельности ННГУ позволяет сделать вывод о ее эффективности и хороших перспективах к расширению географии профориентационных мероприятий и вовлечению в данную сферу влияния ННГУ большего количества ведущих школ Нижегородской области. Также есть перспективы развития системы университетских классов и в соседних регионах.

Профориентационная программа университета предполагает использование разных форматов и технологий взаимодействия с абитуриентами на разных уровнях: непосредственно в школе через проведение лекций преподавателями вуза, в университете через проведение дней открытых дверей, научно-популярных фестивалей и иных массовых мероприятий, а также в процессе выставочной деятельности. Только комплексный подход к решению задачи привлечения в университет талантливых и высокомотивированных к обучению школьников может обеспечить достижение поставленных университетом целей.

Результатом развития интегрированного подхода по внедрению и реализации новых технологий рекрутинговой работы в классическом университете, направленного на поиск одаренных абитуриентов и содействие их дальнейшему развитию в сферах, где наиболее сильны их таланты, станет формирование качественно нового контингента обучающихся. Это даст импульс развитию научно-исследовательских проектов под эгидой ведущих ученых с активным вовлечением в данную деятельность заинтересованных студентов и позволит, массово привлекая талантливых абитуриентов, повысить престиж вузовского образования и создать инновационные и высокотехнологичные образовательные программы и проекты. 
Итогом реализации данного подхода станет:

1) повышение общего уровня образованности, знаний и умений старшеклассников за счет довузовской подготовки, а также плавная адаптация к системе высшей школы;

2) выполнение учащимися научно-исследовательских работ под руководством ведущих преподавателей университета;

3) расширение спектра мероприятий, знакомящих старшеклассников с университетом: экскурсии по музеям университета, дни открытых дверей на факультетах, проведение научно-популярных мероприятий, фестивалей и опен-эйров;

4) внедрение инновационных методов обучения;

5) развитие интернет-ресурсов университета и сетевых научных сообществ под эгидой ННГУ, в том числе активное развитие социально-медийной активности, создание тематических интернет-сообществ с участием преподавателей и исследователей университета, запуск серии научно-популярных лекций молодых ученых университета в формате онлайн под общим названием «Нескучная наука 2.0».

\section{СПИСОК АИТЕРАТУРЫ}

Ефимова, И. Н. (2011) Анализ рынка образовательных услуг с целью выявления мотивации абитуриентов // Вестник Пермского университета. Философия. Психология. Социология. № 4. С. $115-130$.

Ефимова, И. Н., Маковейчук А. В. (2013) Анализ влияния рейтингов вузов на мотивацию абитуриентов // Вестник Нижегородского университета им. Н. И. Аобачевского. № 6-1. C. 27-34.

Ефимова, И. Н., Маковейчук, А. В. (2015) Траектории развития рынка образовательных услуг в условиях глобализации высшего образования и реализации новой государственной образовательной политики в России: прикладной аспект // Вопросы управления. № 3. C. $115-121$.

Колесникова, Г. А. (2009). Особенности спроса на образовательные услуги // Вестник Челябинского государственного университета. № 3 (141). Экономика. Вып. 19. С. 16-18.

Avralev, N., Efimova, I. (2014) Global university rankings as indicators of the implementation of the integration process and competitive tool in the context of globalization of higher education// Life Science Journal. № 11(10). P. 648-652.

Avralev, N., Efimova, I. (2015) University Rankings as a Tool for Assessing the Quality of Education in the Context of Globalization // Asian Social Science. Vol. 11. № 10. P. 292-298.

Duderstadt, J. (2014) The impact of technology on discovery and learning in research universities // Preparing Universities for an Era of Change edited by Weber, L. and J. Duderstadt. Economica Ltd, France. P. 215-219.

Whitehead, F. (2012) Student recruitment strategy: four universities, five key questions [Электронный ресурс] // The Guardian. 13 ноября. URL: https://www.theguardian.com/higher-education-network/blog/2012/nov/13/student-recruitment-strategy-international-universities (дата обращения: 22.02.2017).

Shaw, J. (2013) University recruitment: one fifth of students say social media doesn't work [Электронный ресурс]// The Guardian. 17 апреля. URL: https://www.theguardian.com/higher-education-network/blog/2013/apr/17/ university-student-recruitment-social-media (дата обращения: 24.02.2017).

Russell, P. (2011) Survey Finds Educational Institutions Developing Social Media Policies, Struggling with Resources and Measurement [Электронный ресурс]// Council for Advancement and Support of Education News Release, April 19. URL: http://www.case.org/about_case/newsroom/ press_release_archive/socialmediasurvey2011.html (дата обращения: 23.02.2017).

Schulz, S. A. (2006) Mastering the Admissions Game: Understanding the Enrollment Priorities and Recruitment Strategies of Master's Institutions : Diss. Of $\mathrm{PhD}$ [Электронный ресурc]// UA Campus 
Repository. URL: http://arizona.openrepository.com/arizona/handle/10150/194679 (дата обращения: 23.02.2017).

Аата поступления: 28.02.2017 2.

\author{
OPTIMIZATION OF UNIVERSITY STRATEGY IN THE IMPLEMENTATION \\ OF NEW RECRUITING PROGRAMMES FOR PROSPECTIVE STUDENTS \\ N. V. Avralev, I. N. EFIMOVa, A.V. MakoveychuK \\ LobaCHEVSKY NATIONAL RESEARCH StATE UNIVERSITY OF NIZHNI NOVGOROD
}

In this article, we study the effectiveness of the complex of new-format career guidance activities and the implementation of innovative approaches to the work with university entrants under increasing competition in the field of higher education in Russia. Such approaches include the establishment of mechanisms for the development of school students' research activities and the formation of a continuous education system: school - university. We also analyse the best practices implemented by the Lobachevsky National Research State University of Nizhni Novgorod (UNN named after N. I. Lobachevsky) in this area.

The empirical basis for this article is provided by Lobachevsky University's local documents related to the implementation of the programme «University Education Cluster» and the university's other career guidance activities. Some results of a series of sociological studies conducted at Lobachevsky University during the summer admission campaigns from 2011 to 2016 are also presented. To collect primary data, we used the survey method, which is an effective and illustrative mechanism most commonly used for monitoring customer satisfaction in the context of educational services.

The determining factors that influence the choice made by university entrants include the availability of budget-funded places in the areas of study that they are interested in, the university's location, its facilities, scientific achievements and prestige.

Conclusions are formulated and proposals are made regarding the optimization of the university's career guidance programme, the implementation of new formats and types of activities to attract talented university entrants. Thus, the main areas of work in this direction should be: to expand and deepen partnership relations with the region's leading schools, to implement joint special popular science events in an open-air format, to organize research clubs and quizzes with the participation of highly-cited researchers.

Keywords: university education cluster; recruitment technologies; career guidance; higher education; students; recruitment

\title{
REFERENCES
}

Efimova, I. N. (2011) Analiz rynka obrazovatel'nykh uslug s tsel'iu vyiavleniia motivatsii abiturientov. Vestnik Permskogo universiteta. Filosofiia. Psikbologiia. Sotsiologiia, no. 4, pp. 115-130. (In Russ.).

Efimova, I. N. and Makoveichuk A. V. (2013) Analiz vliianiia reitingov vuzov na motivatsiiu abiturientov. Vestnik Nizhegorodskogo universiteta im. N. I. Lobachevskogo, no. 6-1, pp. 27-34. (In Russ.).

Efimova, I. N. and Makoveichuk, A. V. (2015) Traektorii razvitiia rynka obrazovatel'nykh uslug v usloviiakh globalizatsii vysshego obrazovaniia i realizatsii novoi gosudarstvennoi obrazovatel'noi politiki v Rossii: prikladnoi aspect. Voprosy upravleniia, no. 3, pp. 115-121. (In Russ.).

Kolesnikova, G. A. (2009). Osobennosti sprosa na obrazovatel'nye uslugi. Vestnik Cheliabinskogo gosudarstvennogo universiteta, no. 3 (141). Ekonomika. Vol. 19, pp. 16-18. (In Russ.).

Avralev, N. and Efimova, I. (2014) Global university rankings as indicators of the implementation of the integration process and competitive tool in the context of globalization of higher education. Life Science Journal, no. 11(10), pp. 648-652. (In Russ.).

Avralev, N. and Efimova, I. (2015) University Rankings as a Tool for Assessing the Quality of Education in the Context of Globalization. Asian Social Science, vol. 11, no. 10, pp. 292-298. (In Russ.). 
Duderstadt, J. (2014) The impact of technology on discovery and learning in research universities. In: Preparing Universities for an Era of Change edited by Weber, L. and J. Duderstadt. Economica Ltd, France. P. 215-219.

Whitehead, F. (2012) Student recruitment strategy: four universities, five key questions. The Guardian, 13 November [online] Available at: https://www.theguardian.com/higher-educationnetwork/blog/2012/nov/13/student-recruitment-strategy-international-universities (access date: 22.02.2017).

Shaw, J. (2013) University recruitment: one fifth of students say social media doesn't work. The Guardian, 17 April [online] Available at: https://www.theguardian.com/higher-education-network/blog/2013/apr/17/university-student-recruitment-social-media (access date: 24.02.2017).

Russell, P. (2011) Survey Finds Educational Institutions Developing Social Media Policies, Struggling with Resources and Measurement. Council for Advancement and Support of Education News Release, April 19 [online] Available at: http://www.case.org/about_case/newsroom/ press_release_archive/socialmediasurvey2011.html (access date: 23.02.2017).

Schulz, S. A. (2006) Mastering the Admissions Game: Understanding the Enrollment Priorities and Recruitment Strategies of Master's Institutions : Diss. Of PhD. UA Campus Repository [online] Available at: http://arizona.openrepository.com/arizona/handle/10150/194679 (access date: 23.02.2017).

Submission date: 28.02 .2017$.

Авралев Никита Владимирович - кандидат политических наук, проректор по связям с общественностью Национального исследовательского Нижегородского государственного университета им. Н. И. Аобачевского. Адрес: 603950, Россия, г. Нижний Новгород, пр. Гагарина, 23, корп. 2. Тел.: +7 (831) 462-31-06. Эл. адреc: avralev@unn.ru

Ефимова Ирина Николаевна - кандидат социологических наук, руководитель сектора по связям с общественностью и СМИ отдела по связям с общественностью и интернет-коммуникациям Национального исследовательского Нижегородского государственного университета им. Н. И. Аобачевского. Адрес: 603950, Россия, г. Нижний Новгород, пр. Гагарина, 23, корп. 2. Тел.: +7 (831) 462-31-06. Эл. алрес: pr@unn.ru

Маковейчук Артем Васильевич - ведущий специалист отдела по связям с общественностью и интернет-коммуникациям Национального исследовательского Нижегородского государственного университета им. Н. И. Аобачевского. Адрес: 603950, Россия, г. Нижний Новгород, пр. Гагарина, 23, корп. 2. Тел.: +7 (831) 462-31-07. Эл. адрес: pr@unn.ru

Avralev Nikita Vladimirovich, Candidate of Politology, Vice-Rector for Public Relations, Lobachevsky National Research State University of Nizhni Novgorod. Postal address: 23, Bldg. 2, Gagarina Ave., Nizhny Novgorod, Russian Federation 603950. Tel.: +7 (831) 462-31-06. E-mail:avralev@unn.ru

Efimova Irina Nikolayevna, Candidate of Sociology, Head, Department of Public Relations and Web Communications, Lobachevsky National Research State University of Nizhni Novgorod. Postal address: 23, Bldg. 2, Gagarina Ave., Nizhny Novgorod, Russian Federation 603950. Tel.: +7 (831) 462-31-06.E-mail:pr@unn.ru

Makoveychuk Artyom Vasilyevich, Leading Expert, Department of Public Relations and Web Communications, Lobachevsky National Research State University of Nizhni Novgorod. Postal address: 23, Bldg. 2, Gagarina Ave., Nizhny Novgorod, Russian Federation 603950. Tel.: +7 (831) 462-31-07. E-mail:pr@unn.ru 